\title{
Nasal Septum Morphology in Human Fetuses in Computed TOMOGRAPHY IMAGES
}

\author{
I. Teul ${ }^{1}$, G. Slawinski ${ }^{1}$, J. Lewandowski², E. Dzieciolowska-Baran ${ }^{1}$, A. Gawlikowska-Sroka ${ }^{1}$, F. Czerwinski \\ ${ }^{1}$ Department of Anatomy, Pomeranian Medical University, Szczecin, Poland; \\ ${ }^{2}$ Department of Functional Anatomy, AWF, Poznan, Poland
}

\begin{abstract}
Objectives: Nasal septum deformation (NSD) may cause breathing dysfunction. The reason for a septal deviation is the developmental anomaly in growth of the elastic septum or its skeleton. Such a type of deviation is called physiological. Some deviations can result from the prenatal trauma. The aim of the work was the analysis of the anatomy of the nasal cavity with a special interest focused on the nasal septum and its deviation.

Material and methods: The nasal cavity with its bones and septum was analyzed in CT images of 105 spontaneously aborted fetuses (57 males and 48 females) aged 12 and 40 weeks of gestation. We attempted to assess the morphometric development of the nasal cavity with tomographic scanning methods and to detect anatomical variations.

Results: In 15 (14.3\%) fetuses, NSD were detected on radiological sections. The angle between the virtual line from the sphenoid sinus ostium through limen nasi and the horizontal plane was $33.6 \pm 2.3^{\circ}$, on average.

Conclusions: NSD may already be found in fetuses. The observation of the nasal cavity development enables to evaluate the growth and symmetry of the nasal septum and to foretell predispositions for dysfunction in the upper respiratory tract.
\end{abstract}

Key words: nasal cavity, septum deviation, human fetuses, CT

\section{INTRODUCTION}

Studies of anatomical structures of human fetuses are difficult because of problems related to getting the observation material. Individual and ancestral development of the skull is of great interest of ontogenic anthropology and developmental anatomy. Studies of intra- and interpopulation differences, the mechanism of growth of brain structures, mastication muscles, skull bones, and dynamics and rhythm of development in different periods of progressive development are of great importance of orthodontists, neurologists, obstetricians, and other specialists. Last decades brought lots of information on the human growth in the fetal period mainly thanks to new imaging methods (sonography, MRI, and CT). Also, specific fetal structures of human organism, which control the aerodynamics of the airstream, provide heating, wetting, and cleaning of air, and regulate the development of the skull in particular periods are better known, more detailed, and helpful in an understanding of any developmental failures $[1,2]$. The nose is the central feature of the human face, both anatomically and esthetically in its anatomic structure. Conditions of the nose can be roughly classified in three main groups: congenital, developmental, and acquired [3]. Septal deviation is commonly a result of previous injury; hence deviation is believed to occur as a result of intra-uterine moulding and trauma during parturition [4]. The presence of NSD in fetuses while still in utero also suggests a congenital element $[5,6]$. The type of deformity appears to be determined largely by the period in the course of embryonic development at which the disturbing agent exerts its influence. Recent observations have indicated that maternal infections during pregnancy may be an important factor in pathological conditions of the newborn [7].

Malformations and the results of fetal disease of the nose are often of considerable importance to the survival and future welfare of a child. If severe, they may interfere with breathing, food taking, or both. When these functions are disturbed to a degree which threatens the normal growth of a child, the best possible correction is indicated [8].

\section{Material And Methods}

The study was performed in accord with the Declaration of Helsinki for Human Research and the study protocol was approved by an institutional Ethics Committee.

This study, performed during 2008-2009, was based on fetuses originating from collections of the Department of Anatomy of Medical University in Szczecin and the Department of Functional Anatomy, AWF in Poznan, Poland. To investigate the etiology of nasal septal deviation in 105 (59 males and 46 females) fetal sinonasal specimens aged 12-40 weeks of gestation, ranging from 37 to $374 \mathrm{~mm}$ in length included spontaneously aborted fetuses (Table 1). No deformities and injuries of brain-skull and face-skull, which could influence the development of nasal cavity, were stated. Anthropological data, such as the lengths of the fetuses and skull dimensions were measured. 
Table 1. Age and gender in the studied age-groups of fetuses.

\begin{tabular}{lcccc}
\hline Group & $\begin{array}{c}\text { Age the fetuses } \\
\text { (months) }\end{array}$ & Male & Female & Total \\
\hline Group I & 3.5 & 6 & 4 & 10 \\
Group II & 4.0 & 6 & 4 & 10 \\
Group III & 4.5 & 4 & 4 & 8 \\
Group IV & 5.0 & 5 & 4 & 9 \\
Group V & 5.5 & 6 & 5 & 11 \\
Group VI & 6.0 & 6 & 4 & 10 \\
Group VII & 6.5 & 6 & 6 & 12 \\
Group VIII & 7.0 & 7 & 6 & 13 \\
Group IX & 7.5 & 4 & 5 & 9 \\
Group X & 8.0 & 4 & 2 & 6 \\
Group XI & 8.5 & 2 & 2 & 4 \\
Group XII & 9.0 & 1 & 2 & 3 \\
Total & & 57 & 48 & 105 \\
\hline
\end{tabular}

CT scans were performed in $2.5 \mathrm{~mm}$ sequences from the tip of the anterior nasal spine to the root of the posterior nasal spine. Nasal septum was visible on every scan and could be used as a reference and orientation point in particular scans. Nasal cavities and related structures were examined by means of bilateral dissection. Reference images were obtained in the axial plane with $1 \mathrm{~mm}$ collimation using multi-detector computed tomography (MDCT; Sensation 64, Siemens, Erlangen, Germany) and three-dimensional (axial, sagital, and coronal) reformatted images with $1 \mathrm{~mm}$ thickness were obtained via multiplanar imaging method. Nasal septum was evaluated on the base of CT scans and nasal septum deviation was assessed according to degrees of Mladina's and Cottle's classifications $[9,10]$.

\section{RESULTS}

NSD was observed in 15 fetal heads $(14.3 \%$ of our material). Most of deviations were found in the 5-7 months old age-group (10.3\%). Males were more often affected than females (8.6 and 5.7\%, respectively). Frequency of nasal septum deviation increased from the $4^{\text {th }}$ month of fetal age on. A significant correlation was found between the age of the fetuses and NSD frequency $(\mathrm{F}=2.35, \mathrm{P}=0.0003)$.

Most often observed changes of nasal cavity in CT scans were displacement and deviation of the septal cartilage (Fig. 1). Deviations of type II according to Mladina and straight C- or S- type deviation according to Cottle (mild, vertical deviation of nasal septum) predominated (Fig. 2).

Particular types of deviation were variable and showed changeable frequency in the age-groups. They were more often observed on the left $(9.5 \%)$ than the right side $(4.7 \%)$. In groups IV and VII, deviations of type $1(10.3 \%)$ and type $2(4.2 \%)$ predominated. Septal deformities of the cartilaginous nasal capsule, representing 3\%, were found. The anomalies consisted of curves of the nasal septum. NSD is a reason of asymmetry of nasal cavity (Fig. 3). Asymmetry was stated in anthropometric and tomographic measurements of the facial parts of the fetuses studied (Fig. 4).

In the analyzed fetal nasal cavities, we did not observe deformations of nasal septum due to vertical compression, which may give rise to microtrauma and fracture of the septum. Such microtraumas usually heal by fibrosis, which sometimes creates the processes, called spurs, on the septal surface usually at the borders with the vomer and ethmoid bones.

Following dimensions: high and width of nasal cavity, length of the septum, length, height, and width of

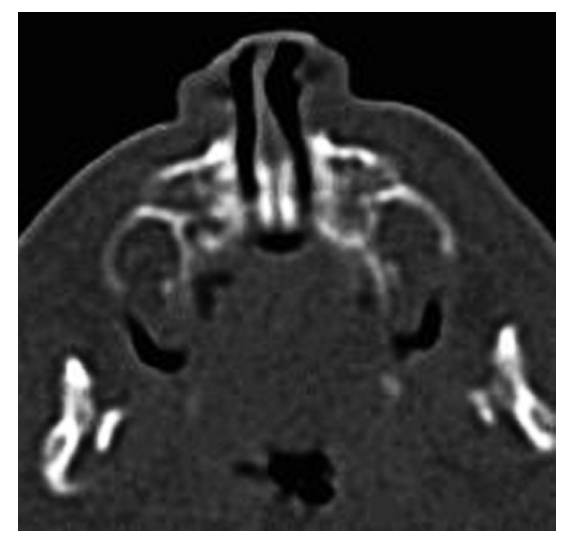

Fig. 1. Displacement and deviation of cartilaginous part of nasal septum.

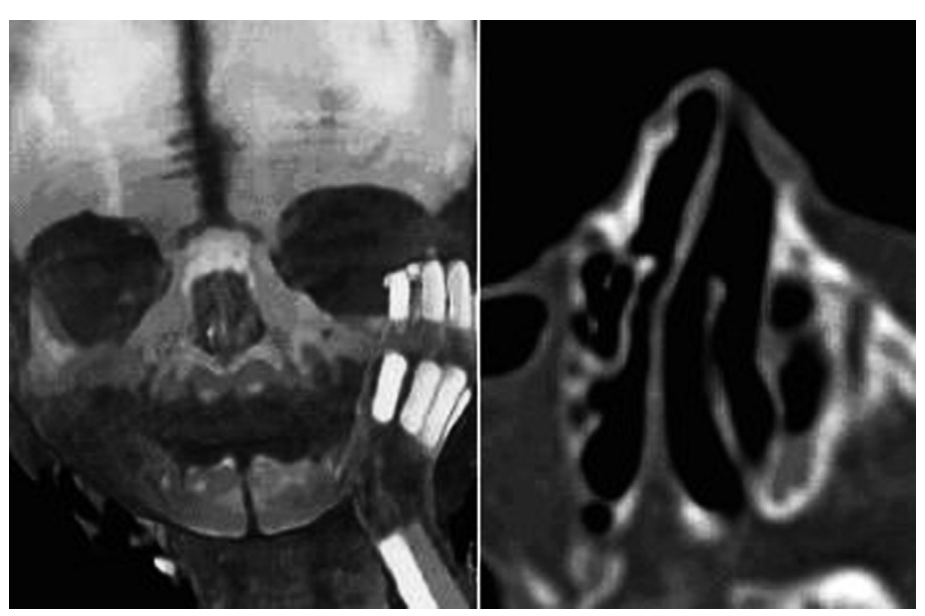

Fig. 2. Left-sided nasal septal deviation; type I (Mladina), type C (Cottle) - causes deviation of the external nose. 


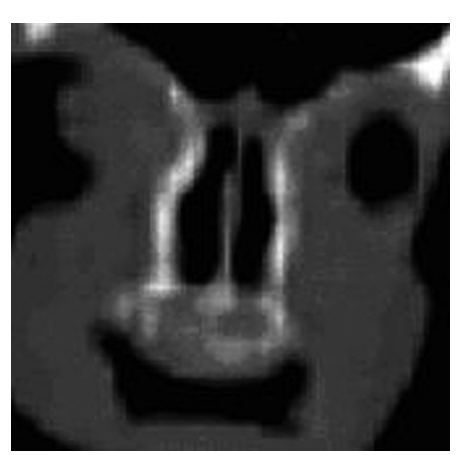

Fig. 3. Asymmetry of the nasal cavity as a result of deviation of the bony part of nasal septum.

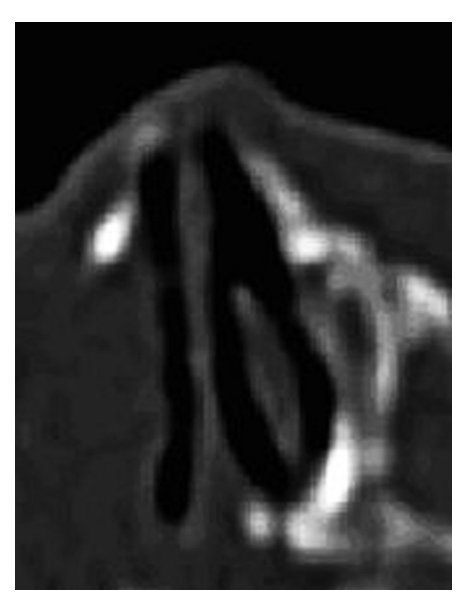

Fig. 4. Asymmetry of the nasal cavity, left-sided deviation of the septum, nasal concha aplasia.

the nose are dependent on the age. The smallest length increase is observed in Group I group: $y=$ $0.51 x+3.22$ and $y=0.50 x+3.24$ for the length of nasal cavity and the length of nasal septum, respectively. In groups GII, GIII, and GIV, dynamics of growth of the face and nasal cavity are comparable, which reveals a constant growth tendency between weeks 17-24 of fetal life and which reaches the highest value in Group $\mathrm{V}$ as shown by the regression equations of $\mathrm{y}=1.04 \mathrm{x}-$ 5.89 and $y=1.09 x-7.91$ for the length of nasal cavity and the length of the face, respectively.

\section{Discussion}

Malformations and deformities of the nose and nasal structures have been resulting from the following: intrauterine and maternal exposures, components of hereditary conditions craniofacial clefs, encephaloceles, trauma in the prenatal and natal life, tumors and tumor ablation, infections, and iatrogenic causes [11, 12]. Recent reports suggest that absence or hypoplasia of the fetal nasal bone, in both the first and second trimesters of pregnancy, is a highly sensitive and specific marker of trisomy $21[13,14]$. Microtraumas and deformities of the nose and different structures of the face skull may be a result of a long-lasting contact with the wall of the uterus or incorrect position of fetus during the fetal development. Cottle [10] differen- tiated temporary flattening and persistent deformation of nasal structures observed during intrauterine development.

Steiner [15] stated that trauma of the nose can be observed from the fourth month of fetal life and suggested that compression of the nose and its structures in the fetal life can be dependent on the position of extremities of the fetus. That notion was supported by the results of the present study, since we did not observe any deviations in the youngest groups of fetuses (Groups I and II, i.e., 3.5-4 months of fetal life). The deviations were observed only in older, larger fetuses which are at greater risk of microtraumas and deformations due to their longer contact with the uterus wall. Similar observations have been described by Jones et al [16] who studied correlations among nasal pyramid deformity, intrauterine stress, and defects in intramembranous ossification.

Unilateral deviations of type I and II, S- or Cshaped nasal cavity in older groups of the studied fetuses could result from a maldevelopment of the vomeropalatal complex, which often is responsible for the formation of nasal septal deviations in fetuses. Similar embryologic explanation has been suggested by Scott [17] and Nishimura [18].

Deviations can be observed in bony and cartilaginous parts of nasal septum [19]. In the present study, both types of deviations were observed, but NSD of the bony part predominated. The main reason seems to be dislocation of the vomer which distorts the septum to one of the sides. We also observed unilateral deviation, mainly to the left side. Yilmaz [20] has similar observation. That author found the incidence of NSD in fetuses of $15 \%$, of which $66 \%$ deviated to the left and 33\% to the right side.

We observed different degrees of deviation, from mild which do not affect the wall of the nasal cavity to severe which press against the lateral wall. The deviations may influence the development of the face-skull to a varied degree, and the severe ones require operative postnatal treatment to enable breathing or to correct the nose shape. Large NSD in fetuses may cause the overgrowth of conchas and bulla ethmoidale on the opposite site. Compression acting on the deviating septum also can press the maxilla, which results in elevating of the floor of the nasal cavity and defective growth of the palate. These defects relate to the future orthodontic problems in children.

In our investigation we did not observe the absence or undergrowth of the nasal bone, which is characteristic of trisomy of the $21^{\text {st }}$ chromosome. A common characteristic of patients with Down syndrome is a flat face with a small nose. In studies which evaluated the association between nasal bone hypoplasia and Down syndrome at 11-14 weeks gestation, nasal ossification was absent in $73 \%$ of Down syndrome fetuses vs. $0.5 \%$ of chromosomally normal fetuses, suggesting that nasal bone evaluation may be useful in screening for Down syndrome [14, 21]. We believe the present study points to a new factor, the congenital one, to the etiology of deformities of the nasal septum in fetuses.

In summary, nasal septal deformations influence the development of other structures of the nasal cavity. Type I and II of NSD were the most frequent de- 
formations in vertical plane. The percentage of type I deformations decreases and that of type II increases with fetal age. Left-sided NSD were more frequent. A straight nasal septum was more frequent in female than in male fetuses. Following up the development of the nose in fetal life can help in recognition of disorders in the growth dynamics of upper airways and congenital diseases.

Acknowledgements: We would to thank to Piotr Rutkowski for technical help and assistance in the study.

Conflicts of interests: The authors declared no conflicts of interests in relation to this article.

\section{REFERENCES}

1. Rosignoli L, Tonni G, Centini G. Cranial development in the first trimester: the use of 3D in the study of complex structures. Imaging Med 2010; 2(3): 251-7.

2. Guis F, Ville Y, Vincent S, Doumerc J, Pons C, Frydman R. Ultrasound evaluation of the length of the fetal nasal bones throughout gestation. Ultrasound Obstet Gynecol 1995; 5: 304-7.

3. Koch B, Castillo M. Sinonasal Diseases. In: Pediatric Neuroradiology, Springer, Berlin Heidelberg 2010; 1391 418.

4. Fulcheria E, Capuab E, Ragnib N. Pregnancy despite IUD: adverse effects on pregnancy evolution and fetus. Contraception 2003; 68(1): 35-38.

5. Bianchi DW, Crombleholme TM, D'Alton ME. Fetology: Diagnosis and Management of the Fetal Patient. McGraw-Hill Professional, USA 2000; 191-241.

6. Nyberg DA, McGahan JP, Pretorium DH. Diagnostic Imaging of Fetal Anomalies. Lippincott Williams \& Wilkins 2003; 335-80.

7. Alpini D, Corti A, Brusa E, Bini A. Septal deviation in newborn infants. Int J Pediatr Otorhinolaryngol 1986; 11(2): 103-7.

8. Neskey D, Eloy JA, Casiano RR. Nasal, septal, and turbinate anatomy and embryology. Otolaryngol Clin North Am 2009; 42(2): 18-20.

9. Mladina R, Bastaic L. What do we know about septal deformities. J Rhinol 1997; 2: 79-89.

10. Cottle M. Concepts of nasal physiology as related to nasal surgery. Arch Otolaryngol 1960; 72: 11.

11. Kvinnsland S. The relationship between the cartilaginous nasal septum and maxillary growth during human fetal life. Cleft Palate J 1970; 7: 523-32.
12. Ruano-Gil D, Montserrat-Viladiu JM, Vilanova-Trias J, Burges-Vila J. Deformities of the nasal septum in human foetuses. Rhinology 1980; 18: 105-9.

13. Gamez F, Ferreiro P, Salmean J M. Ultrasonographic measurement of fetal nasal bone in a low-risk population at 19-22 gestational weeks. Ultrasound Obstet Gynecol 2004; 23: 152-3.

14. Cicero S, Curcio P, Papageorghiou A, Sonek J, Nicolaides $\mathrm{K}$. Absence of nasal bone in fetuses with trisomy 21 at 11-14 weeks of gestation: an observational study. Lancet 2001; 358: 1665-7.

15. Steiner A. A certain aspect of nasal trauma in the prenatal period. Md State Med J 1959; 8: 557.

16. Jones GN, Pringle DR, Yin Z, Carlton MM, Powell KA, Weinstein MB, Toribio RE, KMD La Perle, Kirschner LS. Neural crest-specific loss of Prkar1a causes perinatal lethality resulting from defects in intramembranous ossification. Mol Endocrinol 2010; 24: 6-11.

17. Scott JH. The growth of the nasal cavities. Acta Otolaryngol 1959; 50(3-6): 215-24.

18. Nishimura Y. Embryological study of nasal cavity development in human embryos with reference to congenital nostril atresia. Acta Anat (Basel) 1993; 147(3): 140-4.

19. Manning KP, Singh SD. Hypoplasia of the nasal bones. J Laryngol Otol 1977; 91: 12.

20. Yılmaz NA, Cicekcibasi AE, Emlik D, Y1lmaz MT, Keles B, Salbacak A. Morphometric analyses of the development of nasal cavity in human fetuses: An anatomical and radiological study. Int J Pediatr Otorhinolaryngol 2010; 74(7): 796-802.

21. Fong KW, Toi A, Salem S, Hornberger LK, Chitayat D, Keating SJ, McAuliffe F, Johnson J-A. Detection of fetal structural abnormalities with us during early pregnancy. Radiographics 2004; 24:157-74.

Address for correspondence:

Iwona Teul

Department of Anatomy

Pomeranian Medical University

72, Powstancow Wlkp. St.

70-111 Szczecin

Poland

Phone: +48914661480

E-mail: teul@life.pl 